\title{
NIVEIS DE IMUNIDADE CONTRA A POLIOMIELITE EM UMA AMOSTRA DE ESCOLARES DO MUNICÍPIO DE SÃO PAULO, BRASIL
}

\author{
Klaus E. Stewien* \\ Victório Barbosa** \\ Cornélio P. Rosenburg***
}

RSPU-B/358

STEWIEN, K. E. et al. Niveis de imunidade contra a poliomielite em uma amostra de escolares do municipio de São Paulo, Brasil. Rev. Saúde públ., S. Pallo. $11: 270-8,1977$.

Resumo: A prevalência dos anticorpos protetores contra os três tipos de poliovirus $e$ os niveis de imunidade para os grupos etários de $7,8,9,10,11$, $12,13,14$ e 15 e mais anos de idade foram determinados, por meio de am inquérito soro-epidemiológico, na população escolar do $1^{\circ}$ grau da rede da Prefeitura Municipal de Jão Paulo. O estudo se baseou numa amostra representativa desta populaçáo infantil - exames de 1.489 crianças - e os niveis de imunidade foram determinados em 13 Regtonais Administrativas da Prefeitura. bem como nas três zonas geográficas da capital consideradas - "Centro", "Intermediária" e "Periférica". Os resultados mostraram que apenas cerca da metade das crianças apresentaram anticorpos contra todos os três tipos de poliovirus nos diferentes grupos etários examinados, exceto no grapo de 13 anos, em que a percentagem de iriplo-imunes alcancou $68,0 \%$. Conseqüenıemente, o estadu imunitário da população ainda não alcança os niveis desejáveis de $75 \%$ de triploimunes $e$ a principal causa desta situaçáo foi a prevalência relativamente baixa dos anticorpos contra o poliovirus do tipo 3 , em quase todos os grupos etários examinados. O estudo mostrou também que o estado imunitário da população escolar é semelhante nas três zonas geográficas da capital, havendo, entretanto. diferenças consideráveis nas 13 Regionais Administrativas da Prefeitura, onde as percentagens de crianças triplo-imunes variaram de $38,6 \%$ a $66,9 \%$. Doses de reforco de vacina oral são recomendadas às crianças em idade escolar.

Unitermos: Poliomielite, S. Paulo, Brasil. Imunidade. Inquérito sorológico. Epidemiologia.

\section{N T R O D U ÇA O}

O presente trabalho $f$ i realizado por solicitação e mediante subvenção do Departamento de Assistência Escolar da Secretaria da Educação, da Prefeitura Municipal de
São Paulo. A investigação teve por objetivo principal a determinação do estado imunitário relativo à poliomielite da população escolar do 1 ọ grau da Rede Municipal de

* Do Departamento de Microbiologia e Imunologia do Insttiuto de Ciencias Biomédicas dá USP - Av. Dr. Arnaldo, 715 - São Paulo, SP - Brasil.

* Do Departamento de Epidemiologia da Faculdade de Saúde Pública da USP — Av. Dr. Arnaldo. 715 - São Paulo, SP - Brasil.

*** Do Departamento de Saúde Materno-Infantil da Faculdade de Saúde Pública da USP Ar. Dr. Arnaldo. 715 - São Paulo. SP - Brasil e do Departamento de Assistência ao Escolar da Prefeitura Municipal de São Paulo - Rua Pedra Azul, 314 - São Paulo, SP - Brasil. 
STEWIEN, K, E. et al. - Níveis de imunidade contra a poliomielite em uma amostra de escolares do município de São Paulo, Brasil. Rev. Saúde públ., S. Paulo. 11:270-8, 1977.

São Paulo, visando preencher eventuais lacunas de imunidade através de medidas de vacinação. Os autores resolveram também, na oportunidade, determinar os níveis de imunidade à poliomielite dos escolares de 7 a 15 anos de idade em 13 Regionais Administrativas da Prefeitura, bem como nas 3 zonas geográficas da capital de São Paulo "Centro", "Intermediária" e "Periférica".

Um inquérito soro-epidemiológico recentemente realizado por Barbosa \& Stewien (1976) ${ }^{1}$, na cidade de São Paulo, havia mostrado a apreciável cifra de $42,5 \%$ de crianças totalmente desprotegidas aos 3 tipos de vírus da poliomielite no grupo etário de 9-12 meses de idade. No mesmo estudo verificou-se também que a percentagem de crianças duplo mais triplo-inunes (as que tinham anticorpos protetores contra 2 ou 3 tipos de poliovírus) era de apenas $60 \%$ no grupo etário de $0-5$ anos, considerada insuficiente para controlar a doença.

Estas observaçóes, conjuntamente com a de um aumento nos coeficientes de morbidade da doença paralítica, nos anos de 1971 a 1974, da ordem de 3 vezes, em comparação aos niveis registrados nos anos de 1967 a 1970 , mostraram a necessidade de se manter uma vigilância epidemiológica da poliomielite na cidade de São Paulo ${ }^{1}$. Isto motivou a realização do presente inquérito soro-epidemiológico.

\section{PLANO DE ESTUDO}

\section{Grupo de crianças estudadas}

O grupo em estudo é representado por uma amostra probalistica da população de escolares da $1^{\text {a }}$ à $8^{\text {a }}$ série do $1^{9}$ grau, pertencente à Rede Escolar Municipal de São Paulo. Esta apresenta um total de 256 escolas, localizadas nos diferentes distritos e sub-distritos do Município de São Paulo. A população escolar é composta, em sua maioria, por crianças de baixo nível sócioeconômico, pertencentes aos grupos etários de 7 a 15 anos. As 13 Regionais Administrativas da Prefeitura são compostas pelos seguintes distritos e sub-distritos da capital de São Paulo: 1. VILA MARIANA: Vila Mariana, Indianópolis, e parte de Aclimação, Ibirapuera, Jabaquara, Jardim Paulista, Santo Amaro e Saúde; 2. IPIRANGA: grande parte do Ipiranga, uma parte de Aclimação, Cambuci, Jabaquara, Saúde e Vila Prudente; 3. MOÓCA: Belenzinho, Vila Formosa e grande parte da Moóca e Alto da Moóca, além de parte do Brás, Pari, Tatuapé e Vila Prudente; 4. VILA PRUDENTE: grande parte de Vila Prudente e pequena parte do Alto da Moóca e Itaquera; 5. ERMELINO MATARAZZO e SAO MIGUEL: grande parte de São Miguel Paulista, parte de Ermelino Matarazzo e pequena parte de Itaquera e Guaianazes; 6. FREGUEZIA DO Ó: Brasilândia, Vila Nova Cachoeirinha, grande parte de Casa Verde e Freguezia do Ó, e parte de Santana e Tucuruvi; 7. PIRITUBA-PERUS: Pirituba, Perus, Vila Jaguara, Jaraguá e parte de Nossa Senhora do Ó; 8. BUTAN$T \AA$ : grande parte do Butantã e pequena parte de Ibirapuera e Santo Amaro; 9. CAMPO LIMPO: parte de Santo Amaro e Capela do Socorro e pequena parte do Butantã; 10. PENHA: Penha de França, Cangaiba e parte de Tatuapé, Vila Matilde e Ermelino Matarazzo; 11. ITAQUERAGUAIANAZES: grande parte de Itaquera e Guaianazes, parte de Vila Matilde e pequena parte de São Miguel; 12. SANTANA: Vila Guilherme, Vila Maria, grande parte de Tucuruvi, parte de Santana e pequena parte da Casa Verde; 13. SANTO AMARO: Parelheiros, parte de Santo Amaro, Ibirapuera, Capela do Socorro e pequena parte do Butantã.

A composição das três zonas geográficas da capital consideradas - Centro, Intermediária e Periférica - foi publicada em trabalho anterior 1.

\section{Amostragem}

Foi utilzado um processo sistemático de amostragem de classes, com ponto de partida casual, em que todas as crianças das classes selecionadas foram consideradas 
STEWIEN, $K$. E. et al. - Niveis de imunidade contra a poliomielite em uma amostra de escolares do município de São Paulo, Brasil. Rer. Saúde públ., S. Paulo. 11:270-8, 1977.

amostras. Fez-se uma estratificação das classes com partilha aproximadamente proporcional e, conseqüentemente, obteve-se uma amostra representativa da população de alunos matriculados da Rede Escolar do Município de São Paulo. De unı total de 44 classes sorteadas, obteve-se um total de 1.612 alunos, pertencentes a 41 escolas municipais. Planejou-se que a coleta das informações para preenchimento dos questionários e a coleta das amostras de sangue seriam realizadas em 2 etapas. A primeira acima citada durou aproximadamente 2 meses e a segunda, um mês, correspondendo aos meses de setembro, outubro e novembro de 1974 .

\section{Coleta e apuração dos dados}

As informações necessárias à investigaçãu foram obtidas mediante o preenchimento de questionários abrangendo os itens seguintes: nome, idade, procedência, condição social (habitação), escolaridade da mãe, número de doses de vacina de Sabin (trivalente), idade aproximada em que a criança tomou a primeira e a última dose de vacina e, nos casos em que não recebeu vacina oral, o motivo pelo qual não foi vacinado. Os questionários foram preenchidos por quatro grupos integrados por educadoras sanitárias e professoras primárias do Departamento de Assistência Escolar da Prefeitura de São Paulo, que trabalharam sob courdenação e supervisão constante dos autores. As integrantes dos grupos foram previamente treinadas no preenchimento dos questionários e na técnica de colheita das amostras de sangue (extração digital). Após visita às escolas municipais sorteadas, obteve-se a participação dos diretores e professores das classes para a execução do programa. As informações foram obtidas das mães ou responsáveis das crianças em reuniōes de pais nas escolas, em $70 \%$ dos casos, ou através de visitas domicliares, em $20 \%$ dos casos, e mediante colaboração dos professores, em aproximadamente $10 \%$ dos casos. Foram preenchidos 1.559 questionários, o que representa $96,7 \%$ do total da amostra sorteada. Dos 53 alunos restantes,
52 nāo mais cursavam as suas respectivas escolas e um aluno estava ausente durante toda a fase da coleta de dados, por motivo de doença (meningite).

Após a colheita de sangue dos alunos e a realização das provas sorológicas, obteve-se um total de 1.489 resultados completos, ou seja, 92,4\% do total da amostra.

As informaçōes colhidas e os resultados de laboratório foram transcritos em cartões IBM e apurados por meio do computador Burroughs-B6700, do Centro de Computação Eletrônica da Universidade de São Paulo.

\section{MÉTODOS DE LABORATÓRIO}

\section{Amostras de sangite}

As amostras de sangue foram colhidas nas escolas por extração digital, utilizandose lancetas descartáveis (Redi-Lance, Clay Adams, EUA). De cada criança colhiam-se cerca de 8 gotas de sangue em pequenos tubos estéreis, que eram remetidos no mesmo dia ao laboratório. Separava-se o soro do coágulo após centrifugação da amostra a 1.500 r.p.m., durante $10 \mathrm{~min}$, crum o auxilio do amostrador de Oxford de 25 microlitros (Oxford Laboratories, EUA). Os soros assim obtidos foram congelados a $-20^{\circ} \mathrm{C}$ até serem examinados.

\section{Provas de neutralização}

As provas de neutralização foram realizadas pela microtécnica" Inicialmente os soros eram descongelados e diluídos a 1:10 em meio de Eagle MEM, contendo $200 \mathrm{U}$ por $\mathrm{ml}$ de penicilina $\mathrm{G}$ potássica, 200 microgramas de estreptomicina e 1 micrograma de anfotericina B. As misturas vírus-soro e us controles de vírus e soro eram preparados e incubados em microplacas de poliestireno rígido, com cavidades de fundo chato (Cook Eng., EUA), durante um periodo de meia hora a temperatura ambiente e, a seguir, a $4^{\circ} \mathrm{C}$, durante 18 horas. Uma suspensão de cerca de 400 mil células Hep-2 era então adicionada às misturas e aos controles. As microplacas iam para 
STEWIEN, K. E. et al. - Niveis de imunidade contra a poliomielite em uma amostra de escolares do municipio de São Paulo, Brasil. Rev. Saúde públ., S. Paulo, 11:270-8, 1977.

uma estufa contendo $4-5 \%$ de $\mathrm{CO}$, a temperatura de $36-37^{\circ} \mathrm{C}$. Após o período de incubação de 48 horas, realizava-se a leitura das provas com microscópio invertido (Olympus, Japão).

Considerou-se como resultado positivo de presença de anticorpos toda inibição do efeito citopático igual ou superior a $50 \%$. As estirpes de referência dos três tipos sorológicos foram os protótipos Mahoney (tipo 1), MEF-1 (tipo 2) e Saukett (tipo 3). Os títulos dos vírus variaram no transcurso das diferentes provas de 32 a 250 DICT $_{3 \text {, }}$ (leitura após 48 horas de incubação).

\section{RESULTADOS E DISCUSSAO}

\section{Prevalência de anticorpos e niveis de imunidade}

A prevalência de anticorpos protetores para os grupos etários de 7 a $15 \mathrm{e}+$ anos é apresentada na Figura, em termos de percentagens de crianças triplo-imunes, parcialmente imunes (imunes contra um ou dois tipos de poliovirus) e triplo-susceptiveis aos vírus da poliomielite. Esta Figura mostra também, para os mesmos grupos etários, as percentagens da presença de anticorpos contra os três tipos de poliovirus isoladamente (tipos 1, 2 e 3 ). Verifica-se que nos grupos etários estudados a proporção de triplo-imunes oscila em torno de apenas $50 \%$, exceto no grupo etário de 13 anos. Por outro lado, a proporção de crianças triplo-susceptiveis, isto é, as crianças que não possuem anticorpos contra nenhum dos três tipos de vírus, na diluição de $1: 10$, oscila em torno dos $5 \%$, chegando mesmo a atingir 9\% nos grupos etários maiores (14 e 15 e + anos).

Os resultados obtidos mostram que os níveis de imunidade à poliomielite da população infantil estudada ainda não alcançaram o valor mínimo almejado de $75 \%$ de crianças triplo-imunes. Este nivel de proteção é considerado necessário para o con- trole da doença: Observa-se que apenas o grupo de crianças de 13 anos de idade se destaca dos demais grupos etários, ficando, entretanto, ao nivel de $68 \%$. Este pico de $68 \%$ de triplo-imunes está relacionado com o inicio das campanhas de vacinação em massa na capital de São Paulo no ano de 1962, que atingiu as crianças de 0-4 anos, sendo vacinadas principalmente aquelas com 1 ano de idade. Estas crianças haviam completado os 13 anos por ocasião do presente inquérito (novembro 1974). Nos anos seguintes, quantidades relativamente pequenas de doses de vacina oral foram distribuidas no Municipio de São Paulo, ocorrendo intensificação da vacinação somente a partir de 19671.

Examinando a prevalência dos anticorpos neutralizantes contra os tipos 1, 2 e 3 isoladamente, se nos afigura como satisfatória apenas a percentagem de anticorpos contra o tipo 2 nos diferentes grupos etários estudados. Este resultado, aliás, está de pleno acordo com o maior poder de imunização do virus atenuado de Sabin do tipo 2. Já a prevalência de anticorpos contra o poliovirus do tipo 3 deve ser considerada como precária nos diferentes grupos estudados, exceto no grupo etário de 13 anos. O tipo 1 assume uma posição intermediária entre os três tipos, alcançando niveis satisfatórios (acima de $75 \%$ ) apenas nos grupos etários mais elevados $(13,1+$ e 15 e + anos $)$.

Em virtude da baixa percentagem de positividade de anticorpos neutralizantes contra o tipo 3, uma amostra de 132 soros foi examinada também na diluição de 1:5. Mesmo nesta diluição, $31 \%$ das crianças não apresentaram anticorpos contra o tipo 3 . Resultados semelhantes foram observados em diversas partes do mundo e são atribuídos a uma capacidade imunogênica menor do virus atenuado Leon $12 a_{1} b$ (tipo 3 ) da vacina oral de Sabin 6, 9, 10 assim como a queda acentuada dos niveis séricos nos indivíduos que exibem anticorpos contra o tipo 3 , atingindo valores extremamente baixos ${ }^{2}, 4$. 
STEWIEN, K. E. et al. - Níveis de imunidade contra a poliomielite em uma amostra de escolares do municipio de São Paulo, Brasil. Rev. Saúde públ., S. Paulo, 11:270-8, 1977.

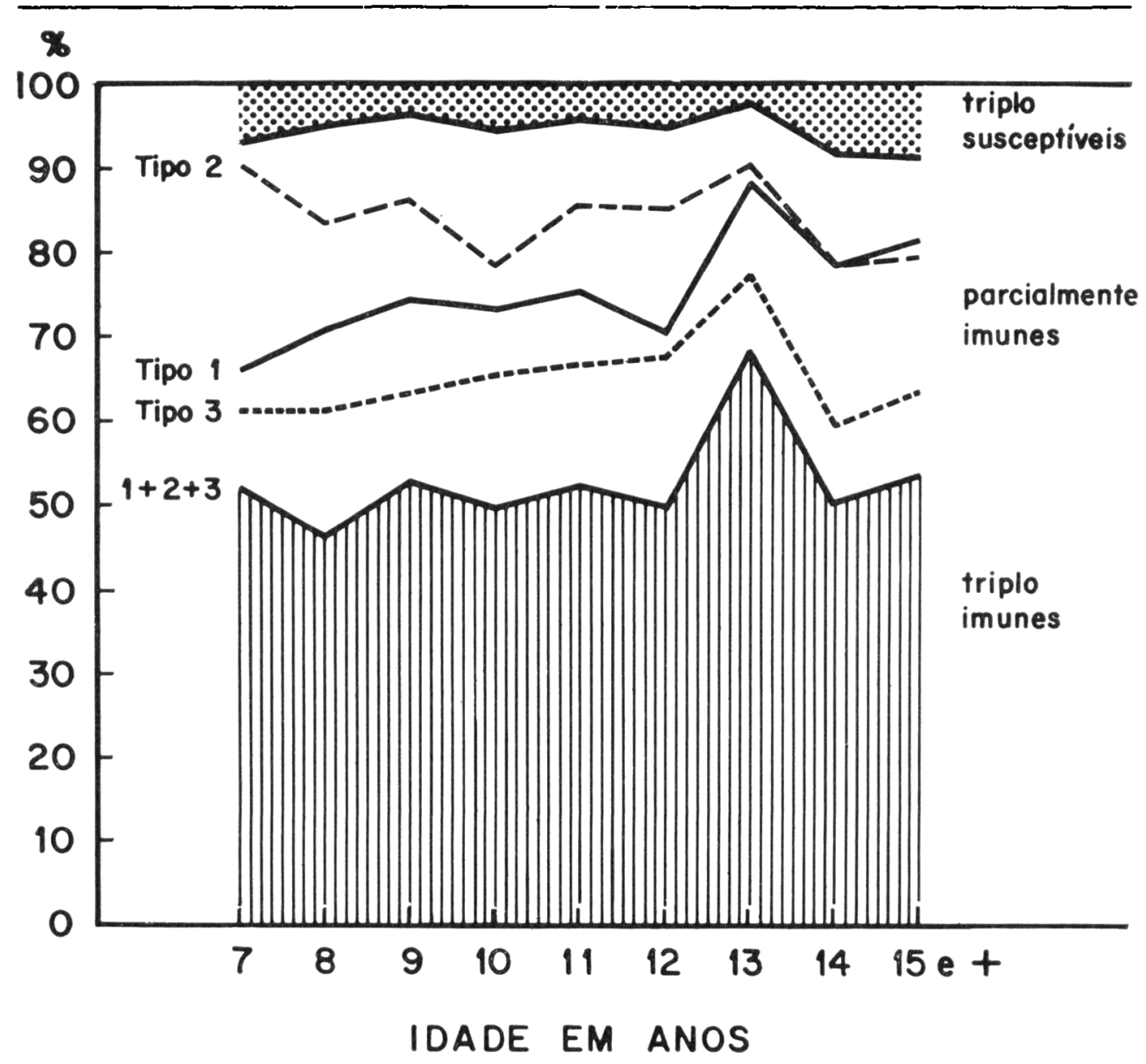

Figura - Prevalência de anticorpos protetores e niveis de imuni lade contra a poliomielite*, população escolar do 10 grau da rede da Prefeitura Municipal de São Paulo, segundo a ida das crianças - 1974

* Imunidade foi definida como 1 título de anticorpos $\geqslant 1: 10$ Susceptibilidade foi definida como um título inferior a $1: 10$

2. Niveis de imunidade e área geográfica

A Tabela 1 apresenta os resultados do inquérito, em termos de crianças duplo mais triplo-imunes, nas três Zonas Geográficas da capital de São Paulo, "Central", "Intermediária" e "Periférica". A análise estatística mostrou que as diferenças no estado imunitário das crianças do 10 grau da Rede Escolar Municipal não são significantes
(Teste do $X^{2}$ ao nivel de $p \geq 0,05$ ). $O$ mesmo resultado foi recentemente observado por Barbosa e Stewien ${ }^{1}$ (1975), em inquérito realizado na população infantil de 0-12 anos, atendida pelo Hospital Menino Jesus da capital de São Paulo. Estes dados certamente são de grande interesse para as nossas autoridades sanitárias e servem de orientação na profilaxia vacinal da poliomielite. 
STEWIEN, K. E. et al. - Niveis de imunidade contra a poliomielite em uma amostra de escolares do município de São Paulo, Brasil. Rev. Saude publ., S. Paulo. 11:270-8, 1977.

T A B E L A 1

Niveis de imunidade à poliomielite, segundo as zonas "Central", "Intermediária" e "Periférica". do município de São Paulo, da população escolar do 1" grau da Rede da Prefeitura Municipal de São Paulo - 1974.

\begin{tabular}{c|c|cc}
\hline Zonas * & Duplo-imunes & Triplo-imunes & $\begin{array}{c}\text { Duplo + Triplo } \\
\text { imunes }\end{array}$ \\
\hline Central & $9 / 31 *-$ & $13 / 31$ & $\mathbf{2 2 / 3 1}$ \\
& $29,0 \%$ & $41,9 \%$ & $70,9 \%$ \\
\hline Intermediária & $171 / 670$ & $354 / 670$ & $\mathbf{5 2 5 / 6 7 0}$ \\
& $25,5 \%$ & $\mathbf{5 2 , 8 \%}$ & $\mathbf{7 8 , 3 \%}$ \\
\hline Periférica & $226 / 788$ & $\mathbf{4 0 3 / 7 8 8}$ & $\mathbf{6 2 9 / 7 8 8}$ \\
& $\mathbf{2 8 , 7 \%}$ & $51,1 \%$ & $79,8 \%$ \\
\hline
\end{tabular}

* Zonas geográficas do município de São Paulo segundo Leser \& Barbosa apud Barbosa \& Stewien $]$

** Número de positivos divididos pelo número de crianças examinadas en determinada zona.

\section{Niveis de imunidade nas Regionais} Administrativas da Prefeitutra

A Tabela 2 apresenta os niveis de imunidade dos escolares do 1 " grau nas 13 Regionais Administrativas da Prefeitura do Município de São Paulo. A percentagem de crianças triplo-imunes variou de $38,6 \%$ até $66,9 \%$, sendo a mediana igual a $48,6 \%$. Os diferentes niveis de imunidades observados não estão correlacionados com 0 número de doses de vacina recebidas pelas crianças, isto é, níveis mais baixos não são necessariamente decorrentes da administração de menores quantidades de vacina $e$ vice-versa. Deve-se este fenômeno à existência de fatores de ordem epidemiológica e operacional, que certamente diferem nas treze Regionais estudadas. Assim, por exemplo, a circulação de poliovirus naturais pode ser maior numa determinada área geográfica do que em outra, o que se reflete na prevalència de anticorpos protetores da população estudada. Por outro lado, a eficiência da vacinação contra a poliomielite pode sofrer variações nas diversas Regionais, levando a niveis diferentes de imunidade.

$O$ presente inquérito evidenciou um total de 211 crianças, ou seja, $14,1 \%$ da população estudada, que não haviam recebido, no passado, nenhuma dose de vacina oral. A Tabela 3 apresenta os motivos referidos pela mãe ou responsável porque os filhos não tomaram a vacina de Sabin. "O desconhecimento da existência da vacina", e "dificuldades de acesso ao Centro de Saúde mais próximo" foram as razóes mais apontadas, totalizando $62,5 \%$ das respostas. Esta observação está a sugerir às nossas autoridades sanitárias que deveriam ser instaladas no município de São Paulo novas unidades sanitárias e postos de vacinação, ambos estrategicamente localizados, visando melhorar a cobertura vacinal contra a poliomielite, respectivamente, nos trabalhos de rotina, bem como durante as campanhas de vacinação em massa. Além disso, sugere também a intensificação da propaganda, divulgação e educação sanitária da população no sentido de fazê-la compreender e aceitar a gravidade do problema da poliomielite entre nós, e, isto conseguido, comparecer às unidades sanitárias e aos postos de vacinaçāo, sempre que oportuno e necessário, levando as suas crianças para receberem a vacina Sabin até completarem o número de doses vacinais que, efetivamente, as tornem imunes à doença paralítica.

Como os níveis de imunidade nas 13 Regionais ainda não alcançam o indice de 
STEWIEN, K. E. et al. - Niveis de imunidade contra a poliomielite em uma amostra de escolares do municipio de São Paulo, Brasil. Rev. Saúde públ., S. Paulo, 11:270-8, 1977.

T A B E L A 2

Níveis de imunidade à poliomielite da população escolar do $1^{\circ}$ grau da rede da Prefeitura do município de São Paulo, segundo as Regionais Administrativas Municipais - 1974.

\begin{tabular}{|c|c|c|c|c|c|c|c|c|c|c|}
\hline \multirow[b]{2}{*}{$\begin{array}{l}\text { Regionais } \\
\text { Administrativas } \\
\text { Municipais }\end{array}$} & \multicolumn{2}{|c|}{$\begin{array}{c}\text { Triplo } \\
\text { Susceptíveis }\end{array}$} & \multicolumn{2}{|c|}{$\begin{array}{l}\text { Mono } \\
\text { imunes }\end{array}$} & \multicolumn{2}{|c|}{$\begin{array}{l}\text { Duplo } \\
\text { imunes }\end{array}$} & \multicolumn{2}{|c|}{$\begin{array}{l}\text { Triplo } \\
\text { imunes }\end{array}$} & \multicolumn{2}{|c|}{$\begin{array}{c}\text { Total } \\
\text { examinado }\end{array}$} \\
\hline & $\mathrm{N}^{\circ}$ & $\%$ & Ne & $\%$ & $\mathrm{~N}^{o}$ & $\%$ & $\mathrm{~N}^{0}$ & $\%$ & Ne & $\%$ \\
\hline 1. Campo Limpo & 2 & 2,9 & 12 & 17,1 & 29 & 41,4 & 27 & 38,6 & 70 & 100 \\
\hline 2. Vila Prudente & 7 & 4,8 & 25 & 17,0 & 51 & 34,7 & 64 & 43,5 & 147 & 100 \\
\hline 3. E. Matarazzo/S. Miguel & 24 & 9,8 & 49 & 19,9 & 63 & 25,6 & 110 & 44,7 & 246 & 100 \\
\hline 4. Ipiranga & 7 & 11,1 & 14 & 22,2 & 13 & 20,6 & 29 & 46,0 & 63 & 100 \\
\hline 5. Mooca & 5 & 15,6 & 4 & 12,5 & 8 & 25,0 & 15 & 46,9 & 32 & 100 \\
\hline 6. Freguesia do ó & 23 & 12,0 & 36 & 18,8 & 41 & 21,5 & 91 & 47,6 & 191 & 100 \\
\hline 7. Vila Mariana & 0 & - & 10 & 28,6 & 8 & 22,9 & 17 & 48,6 & 35 & 100 \\
\hline 8. Butantã & 2 & 3,1 & 7 & 10,9 & 22 & 34,4 & 33 & 51,6 & 64 & 100 \\
\hline 9. Pirituba/Perus & 3 & 2,2 & 14 & 10,3 & 41 & 30,1 & 78 & 57,4 & 136 & 100 \\
\hline 10. Itaquera/Guaianazes & 4 & 3,5 & 16 & 14,0 & 28 & 24,6 & 66 & 57,9 & 114 & 100 \\
\hline 11. Penha & 4 & 2,3 & 20 & 11,4 & 48 & 27,4 & 103 & 58,4 & 175 & 100 \\
\hline 12. Santana & 2 & 2,2 & 6 & 6,5 & 30 & 32,6 & 54 & 58,7 & 92 & 100 \\
\hline 13. Santo Amaro & 1 & 0,8 & 16 & 12,9 & 24 & 19,4 & 83 & 66,9 & 124 & 100 \\
\hline
\end{tabular}

T A B E L A 3

Motivos indicados pelas mães ou responsáveis dos escolares do $1^{\circ}$ grau da rede da Prefeitura Municipal de São Paulo, segundo os quais as crianças não foram vacinadas. São Paulo, 1974.

\begin{tabular}{lcc}
\hline Motivo porque não tomou vacina oral & $\begin{array}{c}\text { Número de } \\
\text { crianças }\end{array}$ & $\begin{array}{c}\text { Freqüência relativa } \\
\text { (percentagem) }\end{array}$ \\
\hline 1. A mãe desconhecia a vacina & 81 & 38,3 \\
2. A mãe residia distante do C. S. & 51 & 24,2 \\
3. A criança estava fora da faixa etária & 18 & 8,5 \\
4. O posto não possuía a vacina & 18 & 8,5 \\
5. A mãe teve medo de vacinar o filho & 12 & 5,9 \\
6. A mãe trabalhava fora & 11 & 5,2 \\
7. A criança estava sempre doente & 7 & 3,3 \\
8. Causa ignorada * & 10 & 4,7 \\
9. Sem resposta & 3 & 1,4 \\
\hline
\end{tabular}

* Não lembra, mãe falecida, criança adotada e outras. 
STEWIEN, K. E. et al. - Niveis de imunidade contra a poliomielite em uma amostra de escolares do municipio de São Paulo. Brasil. Rev. Saúde públ., S. Paulo, 11:270-8, 1977.

proteção desejável, que estaria em torno dos $75 \%$ de indivíduos triplo-imunes, é de se recomendar a administração. de doses de reforço de vacina oral (trivalente), visando manter elevado o nivel de anticorpos no sangue das crianças e preencher as lacunas de imunidade por ventura existentes na população escolar. Seria altamente recomendável vacinar também as gerações futuras com duas doses de reforço, segundo o seguinte esquema: a primeira, por ocasião do ingresso da criança na escola, e a segunda, quando ela se encontra na 7 " ou na $8^{a}$ série.

\section{RSPU-B/358}

STEWIEN, K. E. et al. [Immunity levels to poliomyelitis in a sample of school children from the city of $S$. Patlo, Braztl.] Rev. Saúde públ., S. Paulo, 11: 270-8, 1977.

ABSTRACT: The prevalence of neutralizing antibodies for the three types of polioviruses and the immunity levels of different age groups were determined through a sero-epidemiological survey, in the elementary school children population from the são Paulo public school system. The investigation was based on a representative sample of the school population - a total of $1.48 i$ children was studied - and the immunity levels were determined in 13 Public Administrative Regions, as well as in the three geographical zones of S. Paulo city. The results showed that only about $a$ half of the children had antibodies to all three poliovirus types in the different age groups examined, except in the 13 year age bracket, wheie the percentage of iriple-immunes was $68.0 \%$. Consequently, the immune status of the population does not reach the desirable levels of $75 \%$ of triple positives and the principal cause for this situation was the relative low prevalence of antibodies to the type 3 poliovirus, in almost all the age groups studied. It was also shown that the immune status of the school popullation was similar in the three geographical zones of the city. However, significant differences in immunity were detected in the 13 Public Administrative Regions of $S$. Paulo city, where the percentages of triple positive children varied from $38.6 \%$ to $66.9 \%$. Booster doses of oral vaccine were recommended for children at school age.

Uniterms: Poliomyelitis, S. Paulo, Brazil. Immunity. Serologic, surveys. Epidemiology.

\section{REFERÊNCIAS BIBLIOGRÁFICAS}

1. BARBOSA, V. \& STEWIEN, K. E. Estado imunitário relativo à poliomielite das crianças de 0-12 anos, residentes no município de São Paulo, Brasil e assistidas pelo Hospital Menino Jesus. Rev. Saúde pübl., S. Paulo, 9:137-53. 1975 .

2. COX, H. R. Duration of immunity following live poliovirus vaccine. In: INTERNATIONAL CONFERENCE ON VACCINES AGAINST VIRAL AND RICKETTSIAL DISEASES OF MAN, 19, Washington, D. C., 1966. Papers presented, Washington, D. C., Pan
American Health Organization, 1967. p. 179-84 (PAHO-Scient. publ.. 147).

3. HENNEBERG, G. Probleme der schluckimpfung gegen poliomyelitis, Münch. med. Wschr., 111:1701-7,1969.

4. LENNARTZ, H. \& FISCHER, K. Uberwachung der poliomyelitis-verbreitung in Hamburg. Arch. Hyg. (Berl.), 151:757. 1967.

5. LENNETTE, E. H. \& SCHMIDT, N. J., ed. Diagnostic procedures for viral and rickettsial diseases. 4th ed. New York. American Public Health Association, 1969. 
STEWIEN, K. E. et al. - Niveis de imunidade contra a poliomielite em uma amostra de escolares do municipio de Săo Paulo, Brasil. Rev. Saúde puibl., ડ̇. Paulo, 11:270-8, 1977.

6. MELNICK, J, L. Poliomyelitis vaccine: present status, suggested use, desirable developments. In: INTERNATIONAL CONFERENCE ON THE APPLICATION OF VACCINE AGAINST VIRAL, RICKETTSIAL, AND BACTERIAL DISEASES OF MAN. Washington, D. C., 1970 Washington, D. C., Pan American Health Organization, 1971. p. 171-81. (PAHO-Scient. publ. 226).

7. RAMOS ALVAREZ, $M$, et al. Use of Sabin's live poliovirus vaccine in Mexico: results of a large scale trial, in live poliovirus vaccines, In: INTERNATIONAL CONFERENCE ON LIVE POLIOVIRUS VACCINE. 2nd, Washington. D. C., 1960. Papers presented. Washington, D.C., Pan American Health Organization, 1960. p. 368-409. (PAHO-Scient, publ., 50).
8. SABIN, A. B. Oral poliovirus vaccine J. Amer. med. Ass., 194:872-6, 1965.

9. SKOVRANEK, V, Further observations in conjunction with the first field trial with live poliovirus vaccine in Czechoslovakia: epidemiological study. In: INTERNATIONAL CONFERENCE ON LIVE POLIOVIRUS VACCINE, 2nd, Washington, D. C., 1960. Papers presented. Washington, D. C., Pan American Health Organization, 1960 p. 507-21. (PAHO-Scient. publ,, 50).

10. SWARTZ, T. A. et al. Routine administration of oral polio vaccine in a subtropical area: factors possibly influencing sero-conversion rates. $J$. Hyg., London, 70:719-26, 1972.

Recebido para publicasão em 06/12/1976 Aprovado para publicasão em 17/12/1976

Monson, R. R. \& Hall, A. P. - Mortality among arthritcs. J. Chron. Dis., 29: $459-67,1976$.

A mortalidade por doenças cardio-vasculares não se mostroul inferior entre artriticos, quando comparada com a da população em geral, a despeito do uso intenso de aspirina.

Ravelli, G. P., Stein, Z. A. \& Susser, M. W. - Obesity in young men after famine exposure in utero and early infancy. $N$. Engl. J. Med., 295:349-53, 1976.

A exposição à carência durante a primeira metade da gestação resulta em obesidade significativamente alta nas pessoas delas nascidas. 